Article

\title{
Equity Return Dispersion and Stock Market Volatility: Evidence from Multivariate Linear and Nonlinear Causality Tests
}

\author{
Riza Demirer ${ }^{1, * \mathbb{C}}$, Rangan Gupta ${ }^{2} \mathbb{D},{\text { Zhihui } \mathrm{Lv}^{3} \text { and Wing-Keung Wong }}^{4,5,6}$ \\ 1 Department of Economics \& Finance, Southern Illinois University Edwardsville, School of Business, \\ Edwardsville, IL 62026-1102, USA \\ 2 Department of Economics, University of Pretoria, Pretoria 0002, South Africa; rangan.gupta@up.ac.za \\ 3 KLASMOE \& School of Mathematics and Statistics, Northeast Normal University, Changchun 130024, China; \\ luzh694@nenu.edu.cn \\ 4 Department of Finance, Fintech Center, and Big Data Research Center, Asia University, Taichung 41354, \\ Taiwan; wong@asia.edu.tw \\ 5 Department of Medical Research, China Medical University Hospital, Taichung 40402, Taiwan \\ 6 Department of Economics and Finance, Hang Seng University of Hong Kong, Shatin, \\ Hong Kong 999077, China \\ * Correspondence: rdemire@siue.edu; Tel.: +1-(618)-650-2939
}

Received: 30 October 2018; Accepted: 29 December 2018; Published: 11 January 2019 updates

\begin{abstract}
We employ bivariate and multivariate nonlinear causality tests to document causality from equity return dispersion to stock market volatility and excess returns, even after controlling for the state of the economy. Expansionary (contractionary) market states are associated with a low (high) level of equity return dispersion, indicating asymmetries in the relationship between return dispersion and economic conditions. Our findings indicate that both return dispersion and business conditions are valid joint forecasters of stock market volatility and excess returns and that return dispersion possesses incremental information regarding future stock return dynamics beyond that which can be explained by the state of the economy.
\end{abstract}

Keywords: equity return dispersion; stock market volatility; business cycle; multivariate causality

JEL Codes: C32; E32; G10

\section{Introduction}

Numerous catalysts, ranging from discount rate factors to cash flow and other related variables, can drive fluctuations in stock markets. While stock market fluctuations do not always signal bad news for investors, monitoring and modelling stock market volatility is crucial, not only for investors in their portfolio management and risk assessment models, but also for policy makers in their assessment of financial fundamentals and investor sentiment. Recent literature has documented that equity return dispersion, measured by the cross-sectional standard deviation of stock returns, either at the individual stock or disaggregate portfolio level, carries reliable information regarding the state of the economy and future stock market volatility [1-3]. In another strand of the literature, however, stock market volatility is linked to economic fundamentals [4,5] and the business cycle [6].

Given the ample evidence on the predictive power of equity return dispersion on stock market volatility and the evidence of causality between stock market volatility and the business cycle, a natural research question is whether the predictive power of return dispersion is driven by a common fundamental factor that drives both stock market volatility and the dispersion of stock returns. To that 
end, multivariate causality tests provide a valuable avenue for empirical analysis as we are able to test for causality between return dispersion and stock market premium and volatility after controlling for the state of the economy.

This paper contributes to the literature on stock market predictability by exploring the causal relationship between return dispersion and stock market volatility and excess returns via multivariate nonlinear causality tests recently developed by Bai et al. [7-9] and Chow et al. [10]. The advantage of multivariate causality tests, as opposed to bivariate alternatives that are often employed in the literature, is that it allows us to control for business cycles via the business conditions index that we use in our tests and to examine the causality relationship that bivariate alternatives cannot detect. Given the recent evidence by Choudhry et al. [6] of a bidirectional causal relationship between stock market volatility and the business cycle, the multivariate causality tests that control for business cycles in the causal relationship between return dispersion and stock market volatility allow us to explore whether return dispersion possesses any incremental information regarding stock market return dynamics even after controlling for business cycles, and thus enlarges our understanding of the role of return dispersion as an economic state variable. The issue is of interest not only from the perspective of stock market predictability, but it also has significant applicability to the pricing of derivatives, and hedging and portfolio diversification, as volatility forecasts are an integral part of these exercises. On the other hand, bivariate causality tests could detect the causality relationship between any pair of variables that multivariate causality tests cannot detect. Thus, we employ both bivariate and multivariate causality tests in this study.

Performing a combination of linear vs. nonlinear and bivariate vs. multivariate causality tests, we show that linear causality tests generally fail to detect causal effects from return dispersion to excess market returns and volatility. While observing some evidence of causality from return dispersion to both stock market volatility and excess returns, we observe that causality disappears when we control for the business conditions via the Aruoba-Diebold-Scotti business conditions index. Furthermore, we find that the predictive power of business conditions on return dispersion is concentrated on contractionary periods only, suggesting the presence of asymmetric causal interactions between business conditions, equity return dispersion, and stock market volatility.

Both bivariate and multivariate nonlinear causality tests, however, yield significant evidence of causality from return dispersion to both stock market volatility and equity premium. While detecting significant causality from business conditions to return dispersion, we observe that expansionary (contractionary) market states are associated with a low (high) level of equity return dispersion, in line with the findings in Angelidis et al. [2] that high return dispersion is associated with a deterioration of business conditions. Overall, our findings suggest that both return dispersion and business conditions are valid joint forecasters of both the stock market volatility and excess market return and that return dispersion indeed possesses incremental information regarding future stock return dynamics beyond that which can be explained by the state of the economy. The results have significant implications for stock market forecasting models as well as for policy makers to take into account the cross-sectional variation in stock returns and nonlinearities when assessing the predictors of stock market dynamics.

The rest of the paper is organized as follows. Section 2 provides a brief review of the literature on equity return dispersion in asset pricing and investments. Section 3 presents the data and the methodology for linear and nonlinear multivariate causality tests. Section 4 presents the empirical findings and Section 5 concludes the paper.

\section{Literature Review}

The literature provides ample evidence that associates equity return dispersion with different aspects of risk. In earlier studies focusing on the U.S. stock returns, Christie and Huang [11] and Duffee [12] associated return dispersion with economic expansions and recessions, documenting asymmetries in the cross-sectional dispersion of stock returns with respect to stock market movements and business cycles. Similarly, Loungani et al. [13] found that an index that measures the dispersion 
among stock prices from different industries has predictive power over unemployment. To that end, early research established evidence of an association between equity return dispersion and macroeconomic indicators.

In other works on return dispersion, studies including those of Stivers [14] and Connolly and Stivers [1] established a link between return dispersion, aggregate market volatility, and idiosyncratic volatility, implying that return dispersion provides signals about future aggregate stock market volatility. Further extending the role of return dispersion to asset pricing models, Stivers and Sun [15] and Bhootra [16] associated the time variation in the value and momentum premia with the variation in the market's cross-sectional return dispersion. Similarly, studies including those of Jiang [17], Demirer and Jategaonkar [18], and Demirer et al. [19] showed that return dispersion serves as a systematic risk factor, carrying a positive price of risk in the cross-section of stock returns, while Demirer and Jategaonkar [18] showed that return dispersion risk is asymmetrically priced, conditional on the market return. In a more recent application to G7 countries, Angelidis et al. [2] further supported the role of return dispersion as an economic state variable and showed that return dispersion reliably predicts the time-variation in stock market returns, volatility, as well as the value and momentum premia observed in the cross-section of stock returns. Similarly, Maio [3] showed that return dispersion consistently forecasts a decline in the excess market returns, with superior out-of-sample performance in predicting the equity premium, compared to alternative predictors, including the dividend yield, term spread, etc.

In another strand of the literature that is related to portfolio management, studies including those of Lillo and Mantegna [20], Solnik and Roulet [21], Baur [22], Statman and Scheid [23,24], and Demirer [25] related return dispersion to the association of asset returns and examined the statistic in the context of portfolio diversification. While Baur [22] noted that return dispersion can be used to obtain additional information about market linkages that is not provided by correlation, Eiling and Gerard [26] used a variant of the dispersion measure in order to examine the time variation in linkages among global stock markets.

Meanwhile, another strand of the literature provides ample evidence linking stock market volatility to real economic activity [4,5] and stock market volatility to future aggregate stock returns [27-30]. In a recent study, applying linear and nonlinear causality tests, Choudhry et al. [6] showed that a bidirectional causal relationship exists between stock market volatility and the business cycle in a sample of four major economies without using return dispersion in their multivariate tests.

Building on the recent evidence from asset pricing tests, Chichernea et al. [31] further supported the role of return dispersion as a systematic risk factor and document that return dispersion has explanatory power for accrual and investment anomalies, associating a high level of return dispersion exposure with conditions that are not conducive to growth and investment. A natural research question, therefore, is what drives the predictive value of return dispersion for future returns and volatility and whether this predictive ability is indeed driven by the information return dispersion possesses regarding the state of the economy. To that end, multivariate causality tests provide an interesting opening as they allow us not only to account for possible nonlinearities in the time series, but also to examine the causal associations between return dispersion and stock market return and volatility after controlling for business conditions.

\section{Data and Methodology}

\subsection{Data}

The primary variables of interest in our causality tests are equity return dispersion and stock market volatility, with the Aruoba-Diebold-Scotti business conditions index used as a control variable in our multivariate tests. The sample period covers July 1963 to February 2017, including 13,508 observations of stock and market returns, the Center for Research in Security Prices (CRSP) value-weighted index return, and the one-month Treasury bill rate. From the data, we compute 
equity return dispersion $\left(R D_{t}\right)$ for day $t$ as the cross-sectional standard deviation of daily stock returns calculated as:

$$
R D_{t}=\sqrt{w_{i, t} \sum_{i=1}^{N}\left(r_{i, t}-r_{m, t}\right)^{2}},
$$

where $r_{i, t}$ and $r_{m, t}$ are the return for stock $i$ and the market for day $t$, respectively; $w_{i, t}=1 / N$ for the equally-weighted cross-sectional dispersion of equity returns; and $N$ is the number of stocks. Following Stivers and Sun [15], Angelidis et al. [2], and Maio [3], we compute the cross-sectional standard deviation of daily returns on 100 portfolios sorted on size and book-to-market ratios, obtained from Ken French's website as an estimate for equity return dispersion. Maio [3] argues that the use of portfolios in the computation of return dispersion mitigates estimation errors due to the presence of illiquid and small stocks in the cross-section of individual stocks. Likewise, we obtain data for daily excess returns on the market, defined as the CRSP value-weighted index return minus the one-month Treasury bill rate, from Ken French's website. Please note that as our study builds on the previous studies regarding the predictive power of return dispersion, in particular Angelidis et al. [2] and Maio [3], we compute return dispersion consistent with these studies. This allows us to compare our findings to previous results and focus on the new insight multivariate tests provide; that is, after controlling for business conditions.

Solnik and Roulet [21] used the market model benchmark to show that return dispersion relates to the cross-sectional correlation of asset returns. However, unlike traditional measures of correlation and volatility, return dispersion provides an aggregate measure of co-movement in a portfolio for a given time period. To that end, the equity return dispersion measure in Equation (1) can be regarded as a measure of directional similarity in stock returns for a given day. In the case of stock market volatility, we follow Choudhry et al. [6] and estimate stock market volatility (SV) by means of the univariate generalized autoregressive conditional heteroskedasticity (GARCH $(1,1))$ model of CRSP market index returns. Consistent with Choudhry et al. [6], the computation of SV allows us to compare our findings to the previous findings and provide further insight by adding return dispersion to the multivariate tests. It must be noted that we also tried several alternative models, including the exponential GARCH (EGARCH) and Glosten-Jagannathan-Runkle-GARCH (GJR-GARCH) models, to estimate stock market volatility, and the EGARCH model was found to fit the data better than the GARCH and GJR-GARCH models. However, the results using the EGARCH-based estimates of stock market volatility yielded similar findings for the linear and nonlinear causal relationships in both bivariate and multivariate situations (available upon request).

Figure 1 presents the time series plots for daily equity return dispersion (RD) and stock market volatility (SV) during the sample period. Not surprisingly, we observe several notable spikes in both series, particularly during the Asian crisis period in the late 1990s and the global financial crisis periods, in line with the previous studies associating high stock market volatility with recessionary periods and periods of market stress [4,5]. It is interesting that return dispersion values also exhibit similar spikes during these periods. Demirer et al. [32] note that these periods were also associated with spikes observed in the level of global risk aversion, driving equity market correlations higher globally. To that end, the high level of equity return dispersion observed in Figure 1 during periods when stock market volatility also rises suggests that these two series are possibly driven by a common fundamental factor related to the economy. 


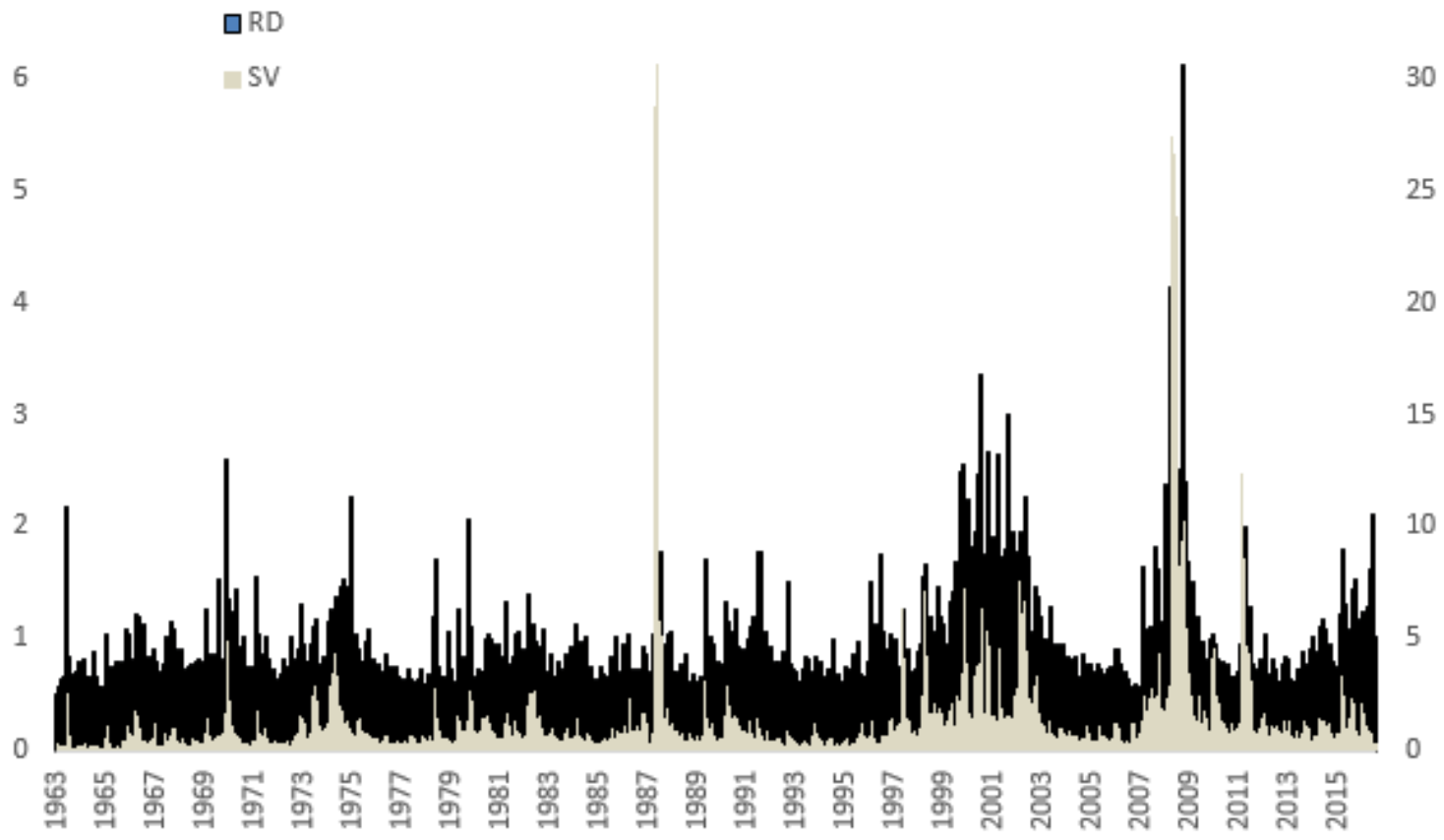

Figure 1. Daily equity return dispersion (RD) and stock market volatility (SV). Note: RD and SV are equity return dispersion and stock market volatility, respectively.

Motivated by studies, including those of Stivers and Sun [15] and Angelidis et al. [2], suggesting that equity return dispersion can predict the time-variation in economic activity, we supplement our multivariate causality tests with the Aruoba-Diebold-Scotti business conditions index (ADS) in order to account for economic conditions in the causal effect of return dispersion on stock market return and volatility. The ADS index developed in Aruoba et al. [33] measures economic activity at high frequency using a dynamic factor model that includes a number of economic variables. We obtain the data for the ADS index from the Philadelphia Fed's website and use this index in our multivariate causality tests in order to track the predictive ability of business conditions along with return dispersion over stock market volatility and premium.

\subsection{Methodology}

\subsubsection{Bivariate Linear Causality Tests}

In order to examine the bivariate linear causal relationship between any pair of equity return dispersion $\left(R D_{t}\right)$, stock market volatility $\left(S V_{t}\right)$, equity market premium $\left(M P_{t}\right)$, business conditions index $\left(A D S_{t}\right)$, and the positive (negative) ADS business conditions index values $\left(A D S 1_{t}\right)\left[\left(A D S 2_{t}\right)\right]$, we let $x_{t}$ and $y_{t}$ present any pair of $R D_{t}, S V_{t}, M P_{t}, A D S_{t}, A D S 1_{t}$, and $A D S 2_{t}$ that we are interested in studying and used the widely accepted vector autoregression (VAR) specification and the corresponding Granger causality test [34]. Consider the following two-equation model:

$$
\begin{aligned}
& x_{t}=a_{1}+\sum_{i=1}^{p} \alpha_{i} x_{t-i}+\sum_{i=1}^{p} \beta_{i} y_{t-i}+\varepsilon_{1 t}, \\
& y_{t}=a_{2}+\sum_{i=1}^{p} \gamma_{i} x_{t-i}+\sum_{i=1}^{p} \delta_{i} y_{t-i}+\varepsilon_{2 t},
\end{aligned}
$$

where $x_{t}$ and $y_{t}$ are stationary variables, $p$ is the optimal lag in the system based on the well-known information criteria, such as the Akaike information criterion (AIC), and $\varepsilon_{1 t}$ and $\varepsilon_{2 t}$ are the disturbances 
satisfying the regularity assumptions of the classical linear normal regression model. The variable $\left\{y_{t}\right\}$ is said not to Granger cause $\left\{x_{t}\right\}$ if $\beta_{i}=0$ in Equation (2a), for any $i=1, \ldots, p$. In other words, the past values of $\left\{y_{t}\right\}$ do not provide any additional information on $\left\{x_{t}\right\}$. Similarly, $\left\{x_{t}\right\}$ does not Granger cause $\left\{y_{t}\right\}$ if $\gamma_{i}=0$ in Equation (2b), for any $i=1, \ldots, p$. In order to test for Granger causality, we used the following null hypotheses separately:

$$
\begin{aligned}
& H_{0}^{1}: \beta_{1}=\beta_{2}=\cdots=\beta_{p}=0, \\
& H_{0}^{2}: \gamma_{1}=\gamma_{2}=\cdots=\gamma_{p}=0,
\end{aligned}
$$

and used the standard F-test to empirically test them.

There are four different situations for the causality relationships between $R D_{t}$ and $S V_{t}$ in Equations (2a) and (2b): (a) Rejecting $H_{0}^{1}$ but not rejecting $H_{0}^{2}$ implies a unidirectional causality from $S V_{t}$ to $R D_{t}$; (b) rejecting $H_{0}^{2}$ but not rejecting $H_{0}^{1}$ implies a unidirectional causality from $R D_{t}$ to $S V_{t}$; (c) rejecting both $H_{0}^{1}$ and $H_{0}^{2}$ implies the existence of feedback relations; and (d) not rejecting both $H_{0}^{1}$ and $H_{0}^{2}$ implies that $R D_{t}$ and $S V_{t}$ are not rejected to be independent. Readers may refer to Bai et al. [7-9], Chow et al. [10], and the references therein for the details of testing $H_{0}^{1}$ and /or $H_{0}^{2}$.

\subsubsection{Nonlinearity Tests}

In this paper, we first perform a linear causality test and thereafter conduct nonlinear causality tests to test whether there is any linear and nonlinear causality among $R D_{t}, S V_{t}, M P_{t}, A D S_{t}, A D S 1_{t}$, and $A D S 2_{t}$. If it is necessary to conduct nonlinear causality tests on the variables, we believe that the residuals obtained from performing the linear causality should contain nonlinearity. In addition, $R D_{t}, S V_{t}, M P_{t}, A D S_{t}, A D S 1_{t}$, and $A D S 2_{t}$ should contain some nonlinear elements so that linear causality cannot eliminate nonlinearity. Thus, in this paper, we conduct a nonlinear test on $R D_{t}$, $S V_{t}, M P_{t}, A D S_{t}, A D S 1_{t}$, and $A D S 2_{t}$. We let $Y_{t}$ represent $R D_{t}, S V_{t}, M P_{t}, A D S_{t}, A D S 1_{t}$, and. In order to test for nonlinearity in the variable $\mathrm{Y}_{\mathrm{t}}$, we first remove the linear components in the series $\left\{\mathrm{Y}_{\mathrm{t}}\right\}$ using an autoregressive (AR) specification and compute the residuals series of $\left\{Y_{t}\right\}$ without loss of generality; we also let $\left\{Y_{t}\right\}$ be the residuals series of $\left\{Y_{t}\right\}$ if there is no confusion. The series $\left\{Y_{t}\right\}$ does not possess any nonlinearity if and only if, for any $t$, the law of corresponding residuals $\left\{Y_{t}\right\}$ satisfies $\mathrm{L}\left(\mathrm{Y}_{\mathrm{t}} \mid \mathrm{Y}_{\mathrm{t}-1}\right)=\mathrm{L}\left(\mathrm{Y}_{\mathrm{t}}\right)$ and we define $\mathrm{C}_{1}(\tau) \equiv \operatorname{Pr}\left(\mathrm{Y}_{\mathrm{t}-1}<\tau, \mathrm{Y}_{\mathrm{t}}<\tau\right), \mathrm{C}_{2}(\tau) \equiv \operatorname{Pr}\left(\mathrm{Y}_{\mathrm{t}-1}<\tau\right)$, and $C_{3}(\tau) \equiv \operatorname{Pr}\left(Y_{t}<\tau\right)$. Since $\operatorname{Pr}\left(Y_{t}<\tau \mid Y_{t-1}<\tau\right)=\frac{C_{1}(\tau)}{C_{2}(\tau)}$, we can test the following hypothesis when testing the existence of the nonlinear of a sequence $\left\{\mathrm{Y}_{t}\right\}$ :

$$
\mathrm{H}_{0}: \frac{\mathrm{C}_{1}(\tau)}{\mathrm{C}_{2}(\tau)}-\mathrm{C}_{3}(\tau)=0
$$

For a residual sequence $\left\{Y_{t}\right\}$, the dependence test statistic is given by:

$$
\mathrm{T}_{\mathrm{n}}=\sqrt{\mathrm{n}}\left(\frac{\mathrm{C}_{1}(\tau, \mathrm{n})}{\mathrm{C}_{2}(\tau, \mathrm{n})}-\mathrm{C}_{3}(\tau, \mathrm{n})\right),
$$

where:

$$
\begin{gathered}
\mathrm{C}_{1}(\tau, \mathrm{n}) \equiv \frac{1}{\mathrm{n}} \sum_{\mathrm{t}=2}^{\mathrm{T}} \mathrm{I}_{\left(\mathrm{y}_{\mathrm{t}-1}<\tau\right)} \cdot \mathrm{I}_{\left(\mathrm{y}_{\mathrm{t}}<\tau\right)}, \\
\mathrm{C}_{2}(\tau, \mathrm{n}) \equiv \frac{1}{\mathrm{n}} \sum_{\mathrm{t}=2}^{\mathrm{T}} \mathrm{I}_{\left(\mathrm{y}_{\mathrm{t}-1}<\tau\right),} \\
\mathrm{C}_{1}(\tau, \mathrm{n}) \equiv \frac{1}{\mathrm{n}} \sum_{\mathrm{t}=2}^{\mathrm{T}} \mathrm{I}_{\left(\mathrm{y}_{\mathrm{t}}<\tau\right),}
\end{gathered}
$$


$\mathrm{n}=\mathrm{T}-1$, and $\mathrm{T}$ is the length of residual $\left\{\mathrm{Y}_{\mathrm{t}}\right\}$. Under this condition, if the residual $\left\{\mathrm{Y}_{\mathrm{t}}\right\}$ is iid, then the test statistic $T_{n} \rightarrow N\left(0, \sigma^{2}(\tau)\right)$, as $n$ is large enough and the hypothesis: $H_{0}: \frac{C_{1}(\tau)}{C_{2}(\tau)}-C_{3}(\tau)=0$ is rejected at level $\alpha$ if $\left|T_{n}\right| / \hat{\sigma}^{2}(\tau)>Z_{\frac{\alpha}{2}}$. In this situation, the series $\left\{Y_{t}\right\}$ possesses any nonlinearity. We note that the nonlinear test takes GARCH effects into consideration in the test (Hui et al. [35] and Bai et al. [9]).

\subsubsection{Multivariate Granger Causality tests}

In this section, we review the theory of both linear and nonlinear causality and discuss how to apply the linear and nonlinear Granger causality tests to identify the causality relationships among $R D_{t}, A D S_{t}, A D S 1_{t}$, and $A D S 2_{t}$ to $S V_{t}$ and $M P_{t}$. To test the linear and nonlinear causality relationship between a vector of stationary variables from $R D_{t}, A D S_{t}, A D S 1_{t}$, and $A D S 2_{t}$ and another vector of stationary variable of either $S V_{t}$ and $M P_{t}$, we let $x_{t}=\left(x_{1, t}, \ldots, x_{n_{1}, t}\right)^{\prime}$ and $y_{t}=\left(y_{1, t}, \ldots, y_{n_{2}, t}\right)$ ' with $n_{1}=2$ and $n_{2}=1, x_{1, t}=R D_{t}, x_{2, t}=A D S_{t}, A D S 1_{t}$, or $A D S 2_{t}, x_{1, t}=S V_{t}$ or $M P_{t}$, and $n_{1}+n_{2}=n$ series in total.

\section{Multivariate Linear Causality}

To test the linear causality relationship between a vector of stationary variables from $x_{t}=$ $\left(x_{1, t}, \ldots, x_{n_{1}, t}\right)^{\prime}$ and $y_{t}=\left(y_{1, t}, \ldots, y_{n_{2}, t}\right) \prime$, one could construct the following $n$ - VAR equations:

$$
\left(\begin{array}{c}
x_{t} \\
y_{t}
\end{array}\right)=\left(\begin{array}{c}
A_{x\left[n_{1} \times 1\right]} \\
A_{y\left[n_{2} \times 1\right]}
\end{array}\right)+\left(\begin{array}{cc}
A_{x x}(L)_{\left[n_{1} \times n_{1}\right]} & A_{x y}(L)_{\left[n_{1} \times n_{2}\right]} \\
A_{y x}(L)_{\left[n_{2} \times n_{1}\right]} & A_{y y}(L)_{\left[n_{2} \times n_{2}\right]}
\end{array}\right)\left(\begin{array}{c}
x_{t-1} \\
y_{t-1}
\end{array}\right)+\left(\begin{array}{c}
e_{x, t} \\
e_{y, t}
\end{array}\right),
$$

where $A_{x\left[n_{1} \times 1\right]}$ and $A_{y\left[n_{2} \times 1\right]}$ are two vectors of intercept terms, and $A_{x x}(L)_{\left[n_{1} \times n_{1}\right]}, A_{y x}(L)_{\left[n_{2} \times n_{1}\right]}$, $A_{x y}(L)_{\left[n_{1} \times n_{2}\right]}$, and $A_{y y}(L)_{\left[n_{2} \times n_{2}\right]}$ are matrices of lag polynomials.

In order to test the following null hypotheses separately:

(1) $H_{0}^{1}: A_{x y}(L)=0$,

(2) $H_{0}^{2}: A_{y x}(L)=0$, and,

(3) both $H_{0}^{1}: A_{x y}(L)=0$ and $H_{0}^{2}: A_{y x}(L)=0$,

We should obtain the residual covariance matrix $\Sigma$ from the full model using an ordinary least squares estimation (OLSE) for each equation without imposing any restriction on the parameters, compute the residual covariance matrix $\Sigma_{0}$ from the restricted model in Equation (6) using OLSE for each equation with the restriction on the parameters imposed by the null hypothesis $H_{0}^{1}, H_{0}^{2}$ or both $H_{0}^{1}$ and $H_{0}^{2}$, and obtain the following statistic:

$$
(\mathrm{T}-\mathrm{c})\left(\log \left|\Sigma_{0}\right|-\log |\Sigma|\right)
$$

where $\mathrm{T}$ is the number of usable observations, $\mathrm{c}$ is the number of parameters estimated in each equation of the unrestricted system, and $\log \left|\Sigma_{0}\right|$ and $\log |\Sigma|$ are the natural logarithms of the determinants of restricted and unrestricted residual covariance matrices, respectively. When the null hypothesis is true, this test statistic has an asymptotic $\chi^{2}$ distribution with the degree of freedom equal to the number of restrictions on the coefficients in the system.

\section{Multivariate Nonlinear Causality}

After applying the VAR model to identify the linear causality relationships from $R D_{t}, A D S_{t}$, $A D S 1_{t}$, and $A D S 2_{t}$ to $S V_{t}$ and $M P_{t}$, we obtain their corresponding residuals $\left\{\hat{\varepsilon}_{1 \mathrm{t}}\right\}$ and $\left\{\hat{\varepsilon}_{2 \mathrm{t}}\right\}$ to test the nonlinear causality with the residual series. For simplicity, in this section, we denote $X_{t}=$ $\left(X_{1, t}, \ldots, X_{n_{1}, t}\right) \prime$ and $Y_{t}=\left(Y_{1, t}, \ldots, Y_{n_{2}, t}\right)^{\prime}$ to be the corresponding residuals of any two vectors of 
variables to be examined. We define the lead vector and lag vector of a time series, say $X_{i, t}$, as follows: for $X_{i, t}, i=1, \ldots, n$, the $m_{x_{i}}$-length lead vector, and the $L_{x_{i}}$-length lag vector of $X_{i, t}$ to be:

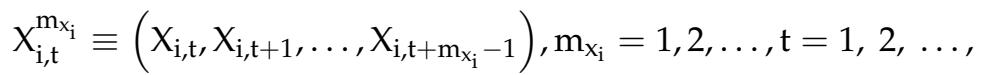

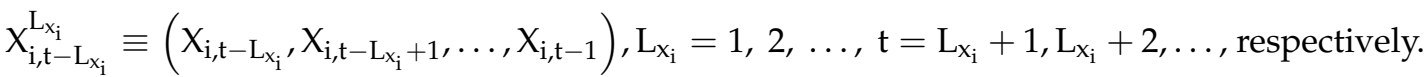

We denote $\mathrm{M}_{\mathrm{x}}=\left(\mathrm{m}_{\mathrm{x} 1}, \ldots, \mathrm{m}_{\mathrm{x}_{n_{1}}}\right), \mathrm{L}_{\mathrm{x}}=\left(\mathrm{L}_{\mathrm{x} 1}, \ldots, \mathrm{L}_{\mathrm{x}_{n_{1}}}\right), \mathrm{m}_{\mathrm{x}}=\max \left(\mathrm{m}_{\mathrm{x} 1}, \ldots, \mathrm{m}_{n_{1}}\right)$, and $\mathrm{l}_{\mathrm{x}}=$ $\max \left(L_{x 1}, \ldots, L_{x_{n_{1}}}\right)$. The $m_{y_{i}}$-length lead vector, $Y_{i, t}^{m_{y_{i}}}$, the $L_{y_{i}}$-length lag vector, $Y_{i, t-L_{y_{i}}}^{L_{y_{i}}}$, of $Y_{i, t}$, and $\mathrm{M}_{\mathrm{y}}, \mathrm{L}_{\mathrm{y}}, \mathrm{m}_{\mathrm{y}}$, and $\mathrm{l}_{\mathrm{y}}$ can be defined similarly.

To test the null hypothesis, $H_{0}$, that $Y_{t}$ does not strictly Granger cause $X_{t}=\left(X_{1, t}, \ldots, X_{n_{1}, t}\right) /$ under the assumptions that the time series vector variables $X_{t}=\left(X_{1, t}, \ldots, X_{n_{1}, t}\right) /$ and $Y_{t}=\left(Y_{1, t}, \ldots, Y_{n_{2}, t}\right)^{\prime}$ are strictly stationary, weakly dependent, and satisfy the mixing conditions stated in Denker and Keller [36], we first defined the following four events given that $m_{x}, m_{y}, L_{x}, L_{y}$, and $e>0$ :

$$
\begin{gathered}
\left\{\left\|X_{t}^{M_{x}}-X_{s}^{M_{x}}\right\|<e\right\} \equiv\left\{\left\|X_{i, t}^{M_{x_{i}}}-X_{i, s}^{m_{x_{i}}}\right\|<e, \text { for any } i=1, \ldots, n_{1}\right\} ; \\
\left\{\left\|X_{t-L_{x}}^{L_{x}}-X_{s-L_{x}}^{L_{x}}\right\|<e\right\} \equiv\left\{\left\|X_{i, t-L_{x_{i}}}^{L_{x_{i}}}-X_{i, s-L_{x_{i}}}^{L_{x_{i}}}\right\|<e, \text { for any } i=1, \ldots, n_{1}\right\} ; \\
\left\{\left\|Y_{t}^{M_{y}}-Y_{s}^{M_{y}}\right\|<e\right\} \equiv\left\{\left\|Y_{i, t}^{m_{y_{i}}}-Y_{i, s}^{m_{y_{i}}}\right\|<e, \text { for any } i=1, \ldots, n_{2}\right\} ; \text { and } \\
\left\{\left\|Y_{t-L_{y}}^{L_{y}}-Y_{s-L_{y}}^{L_{y}}\right\|<e\right\} \equiv\left\{\left\|Y_{i, t-L_{y_{i}}}^{L_{y_{i}}}-Y_{i, s-L_{y_{i}}}^{L_{y_{i}}}\right\|<e, \text { for any } i=1, \ldots, n_{2}\right\} ;
\end{gathered}
$$

where $\|\cdot\|$ denotes the maximum norm which is defined as $\|X-Y\|=$ $\max \left(\left|x_{1}-y_{1}\right|,\left|x_{2}-y_{2}\right|, \ldots,\left|x_{n}-y_{n}\right|\right)$ for any two vectors $\mathrm{X}=\left(x_{1}, \ldots, x_{n}\right)$ and $\mathrm{Y}=\left(y_{1}, \ldots, y_{n}\right)$. The vector series $\left\{Y_{t}\right\}$ is said not to strictly Granger cause another vector series $\left\{X_{t}\right\}$ if:

$$
\begin{gathered}
\operatorname{Pr}\left(\left\|X_{t}^{M_{x}}-X_{s}^{M_{x}}\right\|<e \mid\left\|X_{t-L_{x}}^{L_{x}}-X_{s-L_{x}}^{L_{x}}\right\|<e,\left\|Y_{t-L_{y}}^{L_{y}}-Y_{s-L_{y}}^{L_{y}}\right\|<e,\right) \\
=\operatorname{Pr}\left(\left\|X_{t}^{M_{x}}-X_{s}^{M_{x}}\right\|<e \mid\left\|X_{t-L_{x}}^{L_{x}}-X_{s-L_{x}}^{L_{x}}\right\|<e\right)
\end{gathered}
$$

where $\operatorname{Pr}(\cdot \cdot \cdot)$ denotes conditional probability.

If the null hypothesis, $\mathrm{H}_{0}$, is true, the test statistic:

$$
\sqrt{n}\left(\frac{C_{1}\left(M_{x}+L_{x}, L_{y}, e, n\right)}{C_{2}\left(L_{x}, L_{y}, e, n\right)}-\frac{C_{3}\left(M_{x}+L_{x}, e, n\right)}{C_{4}\left(L_{x}, e, n\right)}\right)
$$

is distributed as $\mathrm{N}\left(0, \sigma^{2}\left(\mathrm{M}_{\mathrm{x}}, \mathrm{L}_{\mathrm{x}}, \mathrm{L}_{\mathrm{y}}, \mathrm{e}\right)\right)$. When the test statistic is too far away from zero, we reject the null hypothesis. Readers may refer to Bai et al. [7-9] and Chow et al. [10] for the definitions of $C_{1}, C_{2}$, $C_{3}$, and $C_{4}$, and more information on the estimates of Equation (9).

\section{Empirical Results}

Although not reported due to space considerations, the summary statistics reveal evidence of non-normality, indicated by highly significant Jarque-Bera statistics, with all four-time series (i.e., $R D_{t}, S V_{t}, A D S_{t}$ and equity market premium, $M P_{t}$ ) exhibiting significant kurtosis. We also observe significant skewness for both $R D_{t}$ and $S V_{t}$, suggesting greater likelihood of experiencing large values for these variables. Finally, in unreported findings, unit root tests based on the augmented Dickey and Fuller [37] show that the series are stationary. 


\subsection{Descriptive Statistics and Stationarity Test}

Before describing the nonlinear causality tests, we first report in Table 1 the basic descriptive statistics and the most commonly used stationarity test, the augmented Dickey-Fuller test, for all the variables $R D_{t}, A D S_{t}, S V_{t}$ and $M P_{t}$, examined in our paper. From the table, we find that the means of all the variables are significantly positive at the 1 percent level except $A D S_{t}$ that is significantly negative at the 1 percent level. The skewness estimates show that $R D_{t}$ and $S V_{t}$ are positively skewed while $A D S_{t}$ and $M P_{t}$ are negatively skewed. Among them, $R D_{t}, A D S_{t}$, and $M P_{t}$ are significant at the 1 percent, while the skewness of $S V_{t}$ is not significant. We also find that all variables have positive excess kurtosis at the 1 percent level. Furthermore, from the skewness, kurtosis, and Jarque-Bera (J-B) test statistics, we conclude that the variables are obviously not normally distributed. The results of the augmented Dickey-Fuller test exhibited in Table 1 do not reject that all variables are strictly stationary. Thus, on the premise of the strictly stationary series, we proceed with the causality analysis.

Table 1. Descriptive statistics and the augmented Dickey-Fuller (ADF) test.

\begin{tabular}{ccccccc}
\hline & Mean & Stdev & Skewness & Kurtosis & J-B & ADF Test \\
\hline$R D_{t}$ & $0.627^{* * *}$ & 0.275 & $4.057^{* * *}$ & $35.136^{* * *}$ & $732,071.353^{* * *}$ & $-8.9165^{* * *}$ \\
$S V_{t}$ & $1.000^{* * *}$ & 1.778 & $8.723^{* * *}$ & $101.069^{* * *}$ & $5,921,984.155^{* * *}$ & $-9.4998^{* * *}$ \\
$M P_{t}$ & $0.025^{* * *}$ & 0.988 & $-0.508^{* * *}$ & $15.633^{* * *}$ & $138,157.710^{* * *}$ & $-82.3209^{* * *}$ \\
$A D S_{t}$ & $-0.018^{* * *}$ & 0.876 & $-1.206^{* * *}$ & $3.921^{* * *}$ & $11,929.823^{* * *}$ & $-7.7651^{* * *}$ \\
\hline
\end{tabular}

Note: $R D_{t}, S V_{t}, M P_{t}$, and $A D S_{t}$ refer to equity return dispersion, stock market volatility, equity market premium, and business conditions index, respectively. This table reports the summary statistics including the mean, standard deviation (s.d.), skewness, excess kurtosis, Jarque-Bera (JB) test, and the augmented Dickey-Fuller test. The symbols $*, * *$, and ${ }^{* * *}$ denote the significance at the $10 \%, 5 \%$, and $1 \%$ levels, respectively.

\subsection{Bivariate Causality Tests}

We begin our discussion by presenting the findings from bivariate causality tests. Table 2 presents the findings for the bivariate linear Granger causality tests. The optimal lag length for each case based on the well-known information criteria, such as Bayesian Information Criterion (BIC) and Akaike Information Criterion(AIC), are also presented along with the test statistics. Examining the findings in Panel A, we observe significant causality from equity return dispersion to both the stock market volatility and equity market premium, consistent with the evidence in Angelidis et al. [2]. Interestingly, however, we see that the causality from return dispersion becomes insignificant after controlling for business conditions measured by the $A D S_{t}$ index. Following the suggestion by Angelidis et al. [2] that a relatively high return dispersion predicts a deterioration in business conditions, we distinguished between good and bad business conditions and created two additional variables $A D S 1_{t}\left(A D S 2_{t}\right)$ representing the positive (negative) $A D S_{t}$ business conditions index values, respectively. However, we see in Panel A that differentiating between good and bad business conditions still yields insignificant causal effects from return dispersion, suggesting that business conditions serve as the primary driver of stock market volatility, rendering the predictive power of return dispersion insignificant.

The findings in Panel B further support these observations, suggesting that business conditions have significant predictive power over both stock market volatility and equity return dispersion. However, interestingly, the predictive power of business conditions is concentrated on contractionary periods only, suggesting asymmetric causal interactions between business conditions, equity return dispersion and stock market volatility. Overall, the findings in Table 2 show that the level of economic activity plays a significant role in studying linear causality from return dispersion to both stock market volatility and equity market premium. 
Table 2. Bivariate linear causality tests.

\begin{tabular}{ccccc}
\hline \multicolumn{5}{c}{ Panel A: The Predictive Power of Equity Return Dispersion } \\
\hline Lags & $R D_{t} \rightarrow S V_{t}$ & $R D_{t} \rightarrow M P_{t}$ & $R D_{t} \rightarrow S V_{t} \mid A D S_{t}$ & $R D_{t} \rightarrow M P_{t} \mid A D S_{t}$ \\
F-Stat & 15 & 9 & 16 & 16 \\
\hline & $188.760^{* * *}$ & $3.196^{* * *}$ & $9.716 \times 10^{-7}$ & $1.136 \times 10^{-8}$ \\
Lags & $R D_{t} \rightarrow S V_{t} \mid A D S 1_{t}$ & $R D_{t} \rightarrow S V_{t} \mid A D S 2_{t}$ & $R D_{t} \rightarrow M P_{t} \mid A D S 1_{t}$ & $R D_{t} \rightarrow M P_{t} \mid A D S 2_{t}$ \\
F-Stat & 9 & 9 & 9 & 9 \\
\hline \multicolumn{5}{c}{ Panel B: The Predictive Power of Business Conditions } \\
\hline Lags & $1.729 \times 10^{-6}$ & $1.714 \times 10^{-6}$ & $1.744 \times 10^{-8}$ & $1.749 \times 10^{-8}$ \\
F-Stat & $A D S 1_{t} \rightarrow S V_{t}$ & $A D S 2_{t} \rightarrow S V_{t}$ & $A D S 1_{t} \rightarrow M P_{t}$ & $A D S 2_{t} \rightarrow M P_{t}$ \\
\hline \multicolumn{7}{c}{16} & 16 & 9 & 9 \\
Lags & 1.146 & $3.579 * * *$ & 0.738 & 1.768 \\
F-Stat & $A D S_{t} \rightarrow R D_{t}$ & $A D S 1_{t} \rightarrow R D_{t}$ & $A D S 2_{t} \rightarrow R D_{t}$ & \\
\hline
\end{tabular}

Note: $R D_{t}, S V_{t}, M P_{t}$ and $A D S_{t}$ refer to equity return dispersion, stock market volatility, equity market premium, and business conditions index, respectively. $A D S 1_{t}\left(A D S 2_{t}\right)$ represents the positive (negative) business conditions index values, respectively. The notation " $\rightarrow$ " indicates causality and " $R D_{t} \rightarrow S V_{t} \mid A D S_{t}$ " indicates causality from $R D_{t}$ to $S V_{t}$ after controlling for $A D S_{t}{ }^{*},{ }^{* *},{ }^{* * *}$ indicate significance at 5,1 , and 0.1 percent level, respectively.

Table 3 presents the results from the nonlinearity tests based on Hui et al. [35] presented in Section 3.2.2. The tests indicate significant evidence of nonlinearity in all-time series at the highest significance level, justifying the use of subsequent nonlinear causality tests. Table 4 presents the results from bivariate nonlinear causality tests. Examining the results in Panels A and B, we observe a significant linear causal relationship from return dispersion to both stock market volatility and equity market premium even after including the $A D S_{t}$ business conditions index. Furthermore, we observe in Panel $C$ that there exists significant causality from business conditions to return dispersion, but with some degree of asymmetry such that expansionary (contractionary) market states are associated with a low (high) level of equity return dispersion, indicating a higher (lower) degree of directional similarity in stock returns, respectively. To that end, the findings from bivariate tests clearly indicate that the predictive power of equity return dispersion over stock market volatility and equity premium is largely asymmetric with regime specific patterns. This finding is indeed significant for not only stock market forecasting models, but also in the pricing of stock options, as volatility forecasts are crucial in pricing derivatives as well as the estimation of optimal hedge ratios.

Table 3. Nonlinearity Tests.

\begin{tabular}{ccccccc}
\hline & $A D S_{t}$ & $A D S 1_{t}$ & $A D S 2_{t}$ & $\boldsymbol{R} \boldsymbol{D}_{t}$ & $S V_{t}$ & $\boldsymbol{M P}_{\boldsymbol{t}}$ \\
\hline Lags & 11 & 10 & 16 & 10 & 15 & 2 \\
T-Stat & $7.734^{* * *}$ & $7.845^{* * *}$ & $7.893^{* * *}$ & $8.970^{* * *}$ & $3.574^{* * *}$ & $8.547^{* * *}$ \\
\hline
\end{tabular}

Note: $R D_{t}, S V_{t}, M P_{t}$ and $A D S_{t}$ refer to equity return dispersion, stock market volatility, equity market premium, and business conditions index, respectively. $A D S 1_{t}\left(A D S 2_{t}\right)$ represents the positive (negative) business conditions index, respectively; ${ }^{* * *}$ indicate significance at 0.1 percent level. 
Table 4. Bivariate nonlinear causality tests.

\begin{tabular}{|c|c|c|c|c|}
\hline \multirow[b]{2}{*}{ Lags } & \multicolumn{4}{|c|}{ Panel A: The Predictability of Stock Market Volatility } \\
\hline & $R D_{t} \rightarrow S V_{t}$ & $R D_{t} \rightarrow S V_{t} \mid A D S_{t}$ & $R D_{t} \rightarrow S V_{t} \mid A D S 1_{t}$ & $R D_{t} \rightarrow S V_{t} \mid A D S 2_{t}$ \\
\hline 1 & $7.879 * * *$ & $7.8190 * * *$ & $7.758^{* * *}$ & $7.824 * * *$ \\
\hline 2 & $7.718^{* * *}$ & $7.665^{* * *}$ & $7.533^{* * *}$ & $7.525^{* * *}$ \\
\hline 3 & $7.637^{* * *}$ & $7.659 * * *$ & $7.533^{* * *}$ & $7.621^{* * *}$ \\
\hline 4 & $7.908^{* * *}$ & $7.871^{* * *}$ & $7.745^{* * *}$ & $7.772 * * *$ \\
\hline 5 & $7.461^{* * *}$ & $7.484^{* * *}$ & $7.309 * * *$ & $7.449 * * *$ \\
\hline 6 & $7.155^{* * *}$ & $7.207^{* * *}$ & $7.141^{* * *}$ & $7.279^{* * *}$ \\
\hline 7 & $6.770 * * *$ & $6.813^{* * *}$ & $6.611^{* * *}$ & $6.662 * * *$ \\
\hline 8 & $6.617^{* * *}$ & $6.721^{* * *}$ & $6.461^{* * *}$ & $6.535^{* * *}$ \\
\hline 9 & $5.984^{* * *}$ & $6.169^{* * *}$ & $5.741^{* * *}$ & $5.884^{* * *}$ \\
\hline \multirow[t]{2}{*}{10} & $5.918^{* * *}$ & $6.067^{* * *}$ & $5.646^{* * *}$ & $5.742 * * *$ \\
\hline & \multicolumn{4}{|c|}{ Panel B: The Predictability of Equity Market Premium } \\
\hline Lags & $R D_{t} \rightarrow M P_{t}$ & $R D_{t} \rightarrow M P_{t} \mid A D S_{t}$ & $R D_{t} \rightarrow M P_{t} \mid A D S 1_{t}$ & $R D_{t} \rightarrow M P_{t} \mid A D S 2_{t}$ \\
\hline 1 & $11.365^{* * *}$ & $11.379 * * *$ & $11.363 * * *$ & $11.302 * * *$ \\
\hline 2 & $12.910^{* * *}$ & $13.079 * * *$ & $12.904^{* * *}$ & $12.877^{* * *}$ \\
\hline 3 & $12.878^{* * *}$ & $13.053^{* * *}$ & $12.867^{* * *}$ & $12.928^{* * *}$ \\
\hline 4 & $13.357^{* * *}$ & $13.643^{* * *}$ & $13.364^{* * *}$ & $13.428^{* * *}$ \\
\hline 5 & $13.275^{* * *}$ & $13.693^{* * *}$ & $13.272^{* * *}$ & $13.420^{* * *}$ \\
\hline 6 & $12.519^{* * *}$ & $12.931^{* * *}$ & $12.527^{* * *}$ & $12.694^{* * *}$ \\
\hline 7 & $11.823^{* * *}$ & $12.206^{* * *}$ & $11.844^{* * *}$ & $12.038^{* * *}$ \\
\hline 8 & $11.805^{* * *}$ & $12.155^{* * *}$ & $11.807^{* * *}$ & $12.048^{* * *}$ \\
\hline 9 & $11.716^{* * *}$ & $11.996^{* * *}$ & $11.695^{* * *}$ & $11.950^{* * *}$ \\
\hline \multirow[t]{2}{*}{10} & $11.104^{* * *}$ & $11.405^{* * *}$ & $11.068^{* * *}$ & $11.321^{* * *}$ \\
\hline & \multicolumn{4}{|c|}{ Panel C: The Predictive Power of Business Conditions } \\
\hline Lags & $A D S_{t} \rightarrow R D_{t}$ & $A D S 1_{t} \rightarrow R D_{t}$ & $A D S 2_{t} \rightarrow R D_{t}$ & \\
\hline 1 & -1.122 & $-5.676^{* * *}$ & $1.755 *$ & \\
\hline 2 & -1.366 & $-6.626^{* * *}$ & $1.808 *$ & \\
\hline 3 & -1.352 & $-6.930^{* * *}$ & $2.627^{* *}$ & \\
\hline 4 & $-2.015^{*}$ & $-6.917^{* * *}$ & $2.317 *$ & \\
\hline 5 & -0.820 & $-4.650 * * *$ & $2.711^{* *}$ & \\
\hline 6 & $-1.718^{*}$ & $-5.231^{* * *}$ & $2.311 *$ & \\
\hline 7 & $-2.147^{*}$ & $-5.412 * * *$ & $2.425^{* *}$ & \\
\hline 8 & $-2.148 *$ & $-4.913^{* * *}$ & $1.708 *$ & \\
\hline 9 & $-1.919 *$ & $-4.669^{* * *}$ & 1.928 * & \\
\hline 10 & $-1.987^{*}$ & $-4.427^{* * *}$ & 1.053 & \\
\hline
\end{tabular}

Note: $R D_{t}, S V_{t}, M P_{t}$ and $A D S_{t}$ refer to equity return dispersion, stock market volatility, equity market premium, and business conditions index, respectively. The notation " $\rightarrow$ " indicates causality and "RD $\rightarrow S V_{t} \mid A D S_{t}$ " indicates causality from $R D_{t}$ to $\mathrm{SV}$ after controlling for $A D S_{t} .{ }^{*}, * * * * *$ indicate significance at 5,1 , and 0.1 percent level, respectively.

\subsection{Multivariate Granger Causality Tests}

Having established evidence suggesting that the level of economic activity plays a significant role in studying causality from return dispersion to both stock market volatility and equity market premium, we now proceed with the multivariate causality tests. Table 5 presents the findings for the multivariate linear Granger causality tests explained in Section 3.2.3. We observe in Panel A that multivariate linear Granger causality exists from the return dispersion and business conditions to stock market volatility at the highest significance level, while the same does not hold for equity market premium, regardless of the distinction between expansionary or contractionary business conditions. 
Table 5. Multivariate linear causality tests.

\begin{tabular}{|c|c|c|c|}
\hline & \multicolumn{3}{|c|}{ Panel A: The Predictability of Stock Market Volatility } \\
\hline & $R D_{t}+A D S_{t} \rightarrow S V_{t}$ & $R D_{t}+A D S 1_{t} \rightarrow S V_{t}$ & $R D_{t}+A D S 2_{t} \rightarrow S V_{t}$ \\
\hline Lags & 10 & 9 & 9 \\
\hline \multirow[t]{3}{*}{ LR } & $535.909 * * *$ & $560.136^{* * *}$ & $573.599 * * *$ \\
\hline & \multicolumn{3}{|c|}{ Panel B: The Predictability of Equity Market Premium } \\
\hline & $R D_{t}+A D S_{t} \rightarrow M P_{t}$ & $R D_{t}+A D S 1_{t} \rightarrow M P_{t}$ & $R D_{t}+A D S 2_{t} \rightarrow M P_{t}$ \\
\hline Lags & 10 & 9 & 9 \\
\hline LR & 37.812 & 37.456 & 39.096 \\
\hline
\end{tabular}

Note: $R D_{t}, S V_{t}, M P_{t}$ and $A D S_{t}$ refer to equity return dispersion, stock market volatility, equity market premium, and business conditions index, respectively. $A D S 1_{t}\left(A D S 2_{t}\right)$ represents the positive (negative) business conditions index values, respectively. The notation " $R D_{t}+A D S_{t} \rightarrow X^{\prime}$ indicates $R D_{t}$ and $A D S_{t}$ together predict variable $\mathrm{X} .{ }^{*}, * *$, *** indicate significance at 5,1 , and 0.1 percent level, respectively.

On the other hand, similar to the findings observed for the bivariate case, when we examine the findings from the multivariate nonlinear tests, presented in Table 6, we observe that equity return dispersion and business conditions together have significant predictive power over both the stock market volatility and equity market premium at the highest statistical significance level. The predictive power of $R D_{t}$ and $A D S_{t}$ together is robust regardless of the state of economic activity, implied by significant findings for both $A D S 1_{t}$ and $A D S 2_{t}$. To that end, our findings underline the significance of nonlinearity in the causal relationship between return dispersion and stock market premium and volatility but also suggest that equity return dispersion along with a measure of economic conditions can be used to improve forecasting models for both return and volatility of stock market returns.

Table 6. Multivariate nonlinear causality tests.

\begin{tabular}{cccc}
\hline \multicolumn{4}{c}{ Panel A: The Predictability of Stock Market Volatility } \\
\hline Lags & $R D_{t}+A D S_{t} \rightarrow S V_{t}$ & $R D_{t}+A D S 1_{t} \rightarrow S V_{t}$ & $R D_{t}+A D S 2_{t} \rightarrow S V_{t}$ \\
\hline 1 & $7.706^{* * *}$ & $7.661^{* * *}$ & $7.614^{* * *}$ \\
2 & $7.59^{* * *}$ & $7.454^{* * *}$ & $7.217^{* * *}$ \\
3 & $7.140^{* * *}$ & $7.286^{* * *}$ & $7.037^{* * *}$ \\
4 & $6.736^{* * *}$ & $7.496^{* * *}$ & $6.565^{* * *}$ \\
5 & $6.321^{* * *}$ & $6.954^{* * *}$ & $5.967^{* * *}$ \\
6 & $5.818^{* * *}$ & $6.610^{* * *}$ & $5.694^{* * *}$ \\
7 & $5.380^{* * *}$ & $6.107^{* * *}$ & $4.963^{* * *}$ \\
8 & $5.447^{* * *}$ & $6.016^{* * *}$ & $4.969^{* * *}$ \\
9 & $4.731^{* * *}$ & $5.387^{* * *}$ & $4.095^{* * *}$ \\
10 & $4.665^{* * *}$ & $5.168^{* * *}$ & $4.108^{* * *}$ \\
\hline
\end{tabular}

Panel B: The Predictability of Equity Market Premium

\begin{tabular}{cccc}
\hline Lags & $R D_{t}+A D S_{t} \rightarrow M P_{t}$ & $R D_{t}+A D S 1_{t} \rightarrow M P_{t}$ & $R D_{t}+A D S 2_{t} \rightarrow M P_{t}$ \\
\hline 1 & $11.271^{* * *}$ & $11.296^{* * *}$ & $11.260^{* * *}$ \\
2 & $12.523^{* * *}$ & $12.655^{* * *}$ & $12.280^{* * *}$ \\
3 & $12.557^{* * *}$ & $12.594^{* * *}$ & $12.370^{* * *}$ \\
4 & $13.092^{* * *}$ & $12.988^{* * *}$ & $12.846^{* * *}$ \\
5 & $12.590^{* * *}$ & $12.727^{* * *}$ & $11.980^{* * *}$ \\
6 & $11.753^{* * *}$ & $11.797^{* * *}$ & $11.288^{* * *}$ \\
7 & $10.6764^{* * *}$ & $10.733^{* * *}$ & $10.478^{* * *}$ \\
8 & $10.749^{* * *}$ & $10.493^{* * *}$ & $10.584^{* * *}$ \\
9 & $10.662^{* * *}$ & $10.577^{* * *}$ & $10.141^{* * *}$ \\
10 & $10.075^{* * *}$ & $9.93^{* * *}$ & $9.601^{* * *}$
\end{tabular}

Note: $R D_{t}, S V_{t}, M P_{t}$ and $A D S_{t}$ refer to equity return dispersion, stock market volatility, equity market premium, and business conditions index, respectively. $A D S 1_{t}\left(A D S 2_{t}\right)$ represents the positive (negative) business conditions index values, respectively. The notation " $R D_{t}+A D S_{t} \rightarrow \mathrm{X}^{\text {" indicates }} R D_{t}$ and $A D S_{t}$ together predict variable $\mathrm{X}$. * **, $* * *$ indicate significance at 5,1 , and 0.1 percent level, respectively. 
Angelidis et al. [2] showed that a relatively high return dispersion predicts a deterioration in business conditions, establishing a link between return dispersion and the business cycle. Therefore, one might be tempted to conclude that the predictive power of return dispersion over stock market volatility is, in fact, driven by its predictive power over the business cycle, which, in turn, is shown to have predictive power over stock market volatility (Choudhry et al. [6]). To this end, multivariate tests allow us to check the robustness of the predictive power of return dispersion by controlling for business conditions in our tests. Therefore, the evidence of causality from return dispersion to stock market volatility even after controlling for business conditions suggests that return dispersion conveys incremental information over stock market volatility beyond which is captured by business conditions. In this sense, it supports the previous findings in Demirer and Jategaonkar [18] and others that return dispersion is more likely to capture shocks related to fundamental economic restructuring, rather than the business cycle. Overall, multivariate tests add new insight that one cannot capture via bivariate counterparts, suggesting that return dispersion possesses incremental predictive content over stock market volatility that business conditions alone cannot capture, and this is an important consideration to improve the accuracy of volatility forecasting models.

\section{Conclusions}

This paper contributes to the literature on stock market predictability by exploring the causal relationships between equity return dispersion, stock market volatility, and excess returns via multivariate nonlinear causality tests recently developed by Bai et al. [7-9]. Performing a combination of linear vs. nonlinear and bivariate vs. multivariate causality tests, we show that linear causality tests generally fail to detect causal effects from return dispersion to excess market returns and volatility. Both bivariate and multivariate nonlinear causality tests, however, yield significant evidence of causality from return dispersion to both stock market volatility and equity premium, even after controlling for the state of the economy. Overall, our findings suggest that both return dispersion and business conditions are valid joint forecasters of both the stock market volatility and excess market return and that return dispersion indeed possesses incremental information regarding future stock return dynamics beyond which can be explained by the state of the economy.

The findings have significant practical implications for the forecasting of stock market volatility dynamics with a possible extension to forecasting risk premia along the lines of Stivers and Sun [15]. As Angelidis et al. [2] note, return dispersion provides a timely and model free estimation of risk. Considering our finding that return dispersion captures incremental information about stock market volatility beyond which can be captured by the level of economic activity, one can use this model-free statistic to improve volatility forecasting models; however, that can only be achieved using nonlinear specifications, as our findings imply. Similarly, the fact that return dispersion offers a timely estimate of risk also allows one to update volatility forecasts in a timely and relatively model-free framework. Furthermore, given the integrated nature of global markets, one can also use return dispersion measures across markets in order to use cross-market dispersion information to improve volatility forecasts in a multi-market setting. This could also lead the path to improved models of co-movement in which return dispersion is used across multiple markets.

There are many directions in which our paper can be extended. One possible extension could include forecasting stock market volatility from equity return dispersion. Future studies could also apply the Copulas approach or other approaches to examine the relationship between equity return dispersion and stock market volatility. So far, to the best of our knowledge, there is no theory explaining whether it is equity return dispersion that causes stock market volatility or it is stock market volatility that causes equity return dispersion or other variables that cause both equity return dispersion and stock market volatility. Thus, another interesting extension is to develop an economic theory to explain the causality between equity return dispersion and stock market volatility. One possible explanation is that it is due to investors' conservative and representative heuristics that relate to the causality 
of both equity return dispersion and stock market volatility; see, for example, Lam et al. [38,39], Fung et al. [40], Guo et al. [41], and the references therein for more information.

Author Contributions: All authors contributed equally in the paper.

Funding: This research received no external funding.

Acknowledgments: The authors are grateful to the Editor-in-Chief, and anonymous referees for substantive comments that have significantly improved this manuscript. The fourth author would like to thank Robert B. Miller and Howard E. Thompson for their continuous guidance and encouragement. This research has been partially supported by grants from Southern Illinois University Edwardsville, University of Pretoria, Northeast Normal University, Asia University, China Medical University Hospital, The Hang Seng University of Hong Kong, the Research Grants Council of Hong Kong (Project Number 12500915), and Ministry of Science and Technology (MOST, Project Numbers 106-2410-H-468-002 and 107-2410-H-468-002-MY3), Taiwan.

Conflicts of Interest: The authors declare no conflict of interest.

\section{References}

1. Connolly, R.; Stivers, C. Information content and other characteristics of the daily cross-sectional dispersion in stock returns. J. Empir. Financ. 2006, 13, 79-112. [CrossRef]

2. Angelidis, T.; Sakkas, A.; Tessaromatis, N. Stock market dispersion, the business cycle and expected factor returns. J. Bank. Financ. 2015, 59, 265-279. [CrossRef]

3. Maio, P. Cross-sectional return dispersion and the equity premium. J. Financ. Mark. 2016, 29, 87-109. [CrossRef]

4. Hamilton, J.D.; Lin, G. Stock market volatility and the business cycle. J. Appl. Econ. 1996, 11, 573-593. [CrossRef]

5. Schwert, G.W. Stock Volatility during the Recent Financial Crisis. Eur. Financ. Manag. 2011, 17, 789-805. [CrossRef]

6. Choudhry, T.; Papadimitriou, F.I.; Shabi, S. Stock market volatility and business cycle: Evidence from linear and nonlinear causality tests. J. Bank. Financ. 2016, 66, 89-101. [CrossRef]

7. Bai, Z.D.; Wong, W.K.; Zhang, B.Z. Multivariate linear and nonlinear causality tests. Math. Comput. Simul. 2010, 81, 5-17. [CrossRef]

8. Bai, Z.D.; Li, H.; Wong, W.K.; Zhang, B.Z. Multivariate Causality Tests with Simulation and Application. Stat. Probab. Lett. 2011, 81, 1063-1071. [CrossRef]

9. Bai, Z.; Hui, Y.; Jiang, D.; Lv, Z.; Wong, W.K.; Zheng, S. A new test of multivariate nonlinear causality. PLoS ONE 2018, 13, e0185155. [CrossRef]

10. Chow, S.C.; Cunado, J.; Gupta, R.; Wong, W.K. Causal Relationships between Economic Policy Uncertainty and Housing Market Returns in China and India: Evidence from Linear and Nonlinear Panel and Time Series Models. Stud. Nonlinear Dyn. Econom. 2018, 22. [CrossRef]

11. Christie, W.; Huang, R. Equity Return Dispersions; Work Paper; Vanderbilt University: Nashville, TN, USA, 1994.

12. Duffee, G.R. Asymmetric Cross-Sectional Dispersion in Stock Returns: Evidence and Implications; U.C. Berkeley: Berkeley, CA, USA, 2001.

13. Loungani, P.; Rush, R.; Tave, W. Stock market dispersion and unemployment. J. Monet. Econ. 1990, 25, 367-388. [CrossRef]

14. Stivers, C.T. Firm-level return dispersion and the future volatility of aggregate stock market returns. J. Financ. Mark. 2003, 6, 389-411. [CrossRef]

15. Stivers, C.; Sun, L. Cross-Sectional Return Dispersion and Time Variation in Value and Momentum Premiums. J. Financ. Quant. Anal. 2010, 45, 987-1014. [CrossRef]

16. Bhootra, A. Are momentum profits driven by the cross-sectional dispersion in expected stock returns? J. Financ. Mark. 2011, 14, 494-513. [CrossRef]

17. Jiang, X. Return dispersion and expected returns. Financ. Mark. Portfol. Manag. 2010, 24, 107-135. [CrossRef]

18. Demirer, R.; Jategaonkar, S. The Conditional Relation Between Dispersion and Return. Rev. Financ. Econ. 2013, 22, 125-134. [CrossRef]

19. Demirer, R.; Jategaonkar, S.P.; Khalifa, A.A. Oil price risk exposure and the cross-section of stock returns: The case of net exporting countries. Energy Econ. 2015, 49, 132-140. [CrossRef] 
20. Lillo, F.; Mantegna, R.N. Variety and Volatility in Financial Markets. Phys. Rev. E 2000, 62, 6126-6134. [CrossRef]

21. Solnik, B.; Roulet, J. Dispersion as cross-sectional correlation. Financ. Anal. J. 2000, 56, 54-61. [CrossRef]

22. Baur, D. Multivariate market association and its extremes. J. Int. Financ. Markets Inst. Money 2006, 16, 355-369. [CrossRef]

23. Statman, M.; Scheid, J. Global Diversification. J. Invest. Manag. 2005, 3, 55-63. [CrossRef]

24. Statman, M.; Scheid, J. Correlation, Return Gaps, and the Benefits of Diversification. J. Portfol. Manag. 2008, 34, 132-139. [CrossRef]

25. Demirer, R. Can Advanced Markets Help Diversify Risks in Frontier Markets? Evidence from Gulf Arab Stock Markets. Res. Int. Bus. Financ. 2013, 29, 77-98. [CrossRef]

26. Eiling, E.; Gerard, B. Dispersion, Equity Return Correlations and Market Integration; University of Toronto: Toronto, ON, Canada, 2011.

27. Goyal, A.; Santa-Clara, P. Idiosyncratic risk matters. J. Financ. 2003, 58, 975-1006. [CrossRef]

28. Bali, T.; Cakici, N.; Yan, X.; Zhang, Z. Does idiosyncratic risk really matter? J. Financ. 2005, 60, 905-929. [CrossRef]

29. Pollet, J.; Wilson, M. Average correlation and stock market returns. J. Financ. Econ. 2010, 96, 364-380. [CrossRef]

30. Garcia, R.; Mantilla-Garcia, D.; Martellini, L. A model-free measure of aggregate idiosyncratic volatility and the prediction of market returns. J. Financ. Quant. Anal. 2014, 49, 1133-1165. [CrossRef]

31. Chichernea, D.C.; Holder, A.D.; Petkevich, A. Does return dispersion explain the accrual and investment anomalies? J. Account. Econ. 2015, 60, 133-148. [CrossRef]

32. Demirer, R.; Omay, T.; Yuksel, A.; Yuksel, A. Global Risk Aversion and Emerging Market Return Comovements. Econ. Lett. 2018, 173, 118-121. [CrossRef]

33. Aruoba, S.; Diebold, F.; Scotti, C. Real-time measurement of business condition. J. Bus. Econ. Stat. 2009, 27, 417-427. [CrossRef]

34. Granger, C.W. Investigating causal relations by econometric models and cross-spectral methods. Econometrica 1969, 37, 424-438. [CrossRef]

35. Hui, Y.C.; Wong, W.K.; Bai, Z.D.; Zhu, Z.Z. A New Nonlinearity Test to Circumvent the Limitation of Volterra Expansion with Application. J. Korean Stat. Soc. 2017, 46, 365-374. [CrossRef]

36. Denker, M.; Keller, G. On U-statistics and v. mise'statistics for weakly dependent processes. Zeitschrift für Wahrscheinlichkeitstheorie und verwandte Gebiete 1983, 64, 505-522. [CrossRef]

37. Dickey, D.A.; Fuller, W.A. Distribution of the estimators for autoregressive time series with a unit root. J. Am. Stat. Assoc. 1979, 74, 427-431.

38. Lam, K.; Liu, T.S.; Wong, W.K. A pseudo-Bayesian model in financial decision making with implications to market volatility, under- and overreaction. Eur. J. Oper. Res. 2010, 203, 166-175. [CrossRef]

39. Lam, K.; Liu, T.S.; Wong, W.K. A New Pseudo Bayesian Model with Implications to Financial Anomalies and Investors' Behaviors. J. Behav. Financ. 2012, 13, 93-107. [CrossRef]

40. Fung, E.S.; Lam, K.; Siu, T.K.; Wong, W.K. A New Pseudo Bayesian Model for Financial Crisis. J. Risk Financ. Manag. 2011, 4, 42-72. [CrossRef]

41. Guo, X.; McAleer, M.; Wong, W.K.; Zhu, L.X. A Bayesian approach to excess volatility, short-term underreaction and long-term overreaction during financial crises, North American. J. Econ. Financ. 2017, 42, 346-358.

(C) 2019 by the authors. Licensee MDPI, Basel, Switzerland. This article is an open access article distributed under the terms and conditions of the Creative Commons Attribution (CC BY) license (http:/ / creativecommons.org/licenses/by/4.0/). 